\title{
Hypoxia in head and neck tumors: characteristics and development during therapy
}

\section{Martin-Immanuel Bittner * and Anca-Ligia Grosu}

Department of Radiation Oncology, University Medical Center Freiburg, Freiburg, Germany

Edited by:

Kwan-Hwa Chi, Shin-Kong Memorial Hospital, Taiwan

\section{Reviewed by:}

Shisuo Du, New York University, USA

K. William Harter, Georgetown

University Medical School, USA

*Correspondence:

Martin-Immanuel Bittner,

Department of Radiation Oncology,

University Medical Center Freiburg

Robert-Koch-Str. 3, 79106 Freiburg, Germany

e-mail: martin-immanuel.bittner@

uniklinik-freiburg.de

\begin{abstract}
Cancers of the head and neck are a malignancy causing a considerable health burden. In head and neck cancer patients, tumor hypoxia has been shown to be an important predictor of response to therapy and outcome. Several imaging modalities can be used to determine the amount and localization of tumor hypoxia. Especially PET has been used in a number of studies analyzing this phenomenon. However, only few studies have reported the characteristics and development during (chemoradio-) therapy. Yet, the characterization of tumor hypoxia in the course of treatment is of great clinical importance. Successful delineation of hypoxic subvolumes could make an inclusion into radiation treatment planning feasible, where dose painting is hypothesized to improve the tumor control probability. So far, hypoxic subvolumes have been shown to undergo changes during therapy; in most cases, a reduction in tumor hypoxia can be seen, but there are also differing observations. In addition, the hypoxic subvolumes have mostly been described as geographically rather stable. However, studies specifically addressing these issues are needed to provide more data regarding these initial findings and the hypotheses connected with them.
\end{abstract}

Keywords: tumor hypoxia, head and neck tumors, primary chemoradiotherapy, biological imaging, PET

\section{INTRODUCTION: RELEVANCE OF TUMOR HYPOXIA}

Cancers of the head and neck are a frequent malignancy, causing a high burden of disease with a median 5 year survival of around $50 \%$ (1). Tumor hypoxia has been shown to be a negative prognostic factor for cancers of the head and neck, being associated with reduced therapeutic effect of radiotherapy and decreased overall survival (2-7). This is explained by decreased sensitivity toward radiation and reduced accessibility for chemotherapy (1, 8). Therefore, tumor hypoxia is an important phenomenon in radiation oncology.

\section{IMAGING MODALITIES}

Novel imaging techniques have the potential to improve the therapeutic setting (9). 18-F-MISO-PET is probably the most commonly used and best validated tracer for hypoxia imaging so far (8). Gagel et al. (10) and Zimny et al. (11) found good correlations with $\mathrm{pO}_{2}$-polarography measurements in cancers of the head and neck. However, Mortensen et al. (12) were not able to confirm these results. It can be hypothesized that the different methods used for defining hypoxia all have their limitations (13).

Other PET tracers have also been proposed or used for hypoxia imaging in cancers of the head and neck, such as 18-F-FAZA (14, 15), 62-Cu-ATSM (16), 18-F-EF5 (17), or 18-F-HX4 (18). However, the superiority of certain tracers still remains to be elucidated. Another option is the use of dynamic PET imaging data, as proposed by several groups $(19,20)$. Interpreting the dynamic data can be challenging, given the fact that the models currently in use differ in the results obtained and conclusions drawn, as shown for a model comparison in a patient set (21). Further imaging modalities are amongst several others dynamic contrast enhanced MRI (22) or perfusion CT (23).
Most studies so far correlated one set of pre-treatment imaging data with the clinical outcome or another parameter of interest. This review however is dedicated to analyze the characteristics and development of hypoxic subvolumes during therapy, thus examining the results of serial imaging with special attention to possible implications for radiation treatment planning.

\section{CHARACTERISTICS OF HYPOXIC SUBVOLUMES AND DEVELOPMENT DURING THERAPY}

In the classical concept of tumor hypoxia, acute and chronic hypoxia can be differentiated. The former results from short-term perfusion changes whereas the latter is a consequence of a limited diffusion capacity of oxygen from the non-physiological tumor vessels (8). However, evidence regarding the changes of the hypoxic subvolumes during (chemoradio-) therapy remains scarce. Given the prognostic importance and the potential therapeutic consequences (e.g., alteration of radiotherapy, additional drugs), the analysis of tumor hypoxia has to be regarded as an important field of research.

Most studies report that during or after therapy residual or even increasing hypoxia is generally less frequent than decreasing or resolving hypoxia: Rischin et al. (5) found residual hypoxia in six out of 28 patients (pre-treatment vs. week 4 or 5), Lee et al. (24) found residual hypoxia in two out of 18 patients (pre-treatment vs. week 4) and Zips et al. (25) found residual hypoxia in 10 out of 24 patients (pre-treatment vs. week 5).

In contrast, higher proportions of residual hypoxia were found by Dirix et al. (26): four out of eight patients showed residual hypoxia (pre-treatment vs. week 4). In another study, residual hypoxia was detected in six out of 13 patients (pre-treatment vs. week 2-4) with hypoxic subvolumes at the same location, but 
smaller in size (27). Sometimes, however, hypoxic subvolumes can be so small that detailed reports regarding the behavior during therapy cannot be given; this was the case for a study including four patients with head and neck cancers, with hypoxic subvolumes between 0.0 and $2.7 \%$ (28).

In general, a remarkable reduction in tumor hypoxia in the course of treatment is a finding common to most studies performed so far.

As stated above, hypoxia remaining at the same location (but frequently decreasing in size) has been described before. Zips et al. (25) assessed the development of the hypoxic subvolumes in the course of chemoradiotherapy in four subsequent 18-F-MISOPET-scans and also showed three different types of behavior: stable hypoxia, decreasing hypoxia, and increasing hypoxia (see Figure 1 for a schematic display of the different findings, also including other studies' results).

A study dedicated at assessing the time-course of hypoxia during therapy has recently confirmed these types of behavior, at the same time adding new aspects: five out of 16 patients showed persistent hypoxia in serial 18-F-MISO-PET imaging and were subsequently analyzed in detail (29). In addition to the general types of behavior stated above, a stationary and a dynamic component were described. They refer to the degree of overlap of the hypoxic subvolumes in the course of treatment (pre-treatment vs. week 2). A stationary component was present in 4 of 5 and a dynamic component in 3 of 5 patients. These two labels are not mutually exclusive, since increasing hypoxia can also migrate into volumes which were not hypoxic before. Overall, a geographically rather stable conformation was found in the majority of patients (29).

The dynamic component has also been studied before: according to Lin et al. (30) and Nehmeh et al. (31), only 7 out of 13 patients showed a high $(R \geq 0.5)$ correlation between hypoxic subvolumes in two 18-F-MISO-PET-scans made 3 days apart, therefore excluding the effect of therapy. This has been interpreted as an indicator of on-going within-voxel changes of oxygenation status. Contrasting results have been obtained by Okamoto et al. (32), who found a high reproducibility of two 18-F-MISO-PET-scans made 2 days apart. However, simulation data indicate that acute hypoxia does not affect the reproducibility of 18-F-MISO-uptake in hypoxic subvolumes (33). Toma-Dasu et al. (34) proposed a mathematical algorithm based on a single 18-F-MISO-PET-scan prior to treatment to identify presumably more radioresistant subvolumes. This is clearly a field which needs further research.

Polarographic data also showed that oxygenation status/hypoxia can change in several ways in the course of treatment: Stadler et al. (35) found both increases and decreases of the hypoxic fraction. Similarly, dynamic imaging data also showed both decreasing and increasing hypoxia (36). Another way to analyze dynamic image data is by giving curves, representing accumulation, intermediate and wash-out types of hypoxia (37). In this study, a majority of patients (11 of 14) showed a decrease in tumormuscle ratio. A clear qualitative decrease in tumor hypoxia over 4 weeks of treatment was also reported by another study (38).

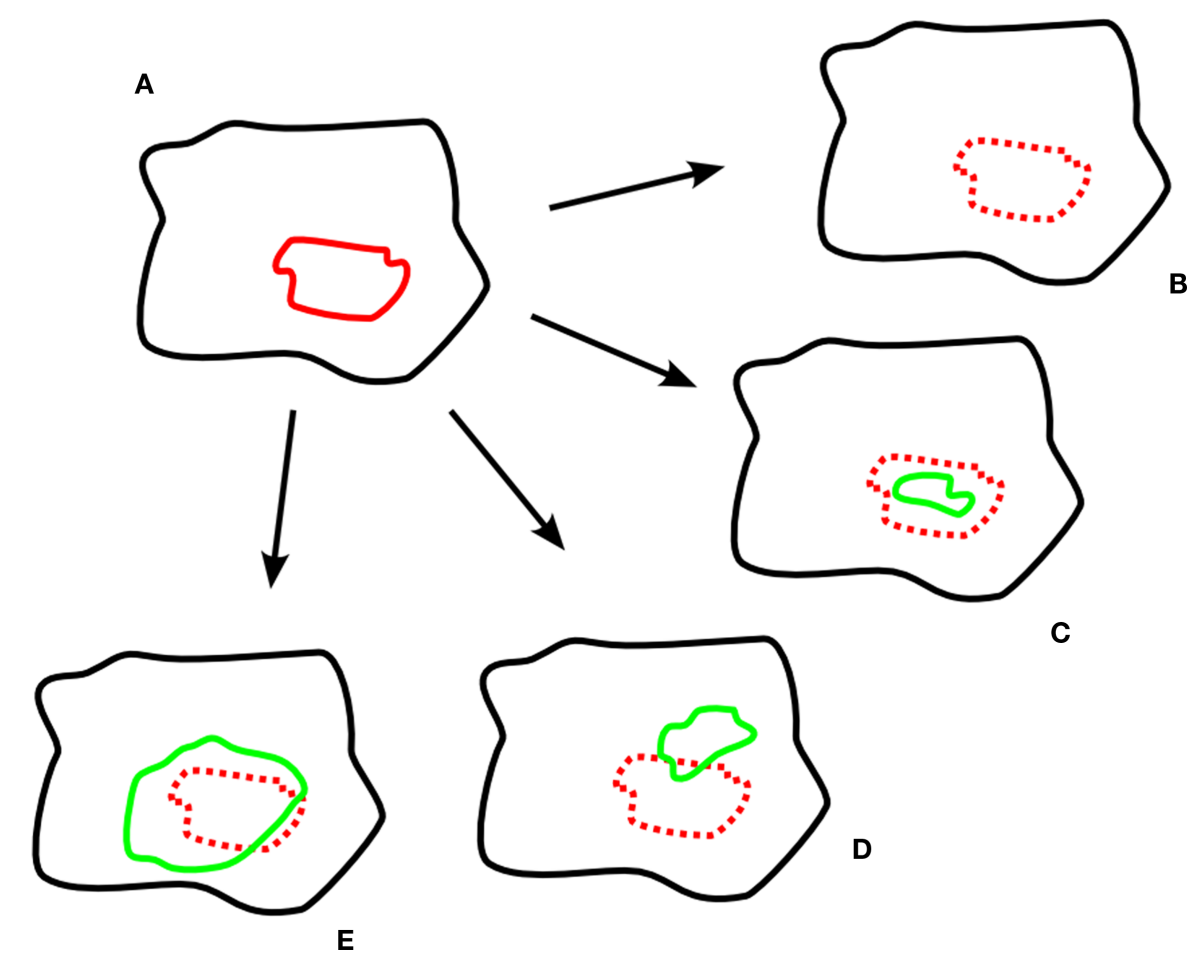

FIGURE 1 | Exemplary schematic hypoxia imaging scans. (A) pre-treatment; (B-E) different developments during treatment; (B) resolved hypoxia; (C) decreased, geographically stable hypoxia; (D) decreased, geographically unstable hypoxia; (E) increased hypoxia. Legend: black: tumor volume; red: hypoxic subvolume pre-treatment; green: hypoxic subvolume during treatment. 
It has also been reported that acute (changing) and chronic (stable) hypoxia can be modeled in serial 18-F-MISO-PET imaging using Gaussian and Poisson distributions (39). In this study, acute hypoxia accounted for an average amount of $34 \%$. Again, this indicates a higher proportion of stable or chronic as opposed to changing tumor hypoxia.

Recently, it has been proposed that fluctuating hypoxia is also important because it may maintain cancer stem cells (40). This hypothesis clearly needs further confirmatory work, but it highlights the significance of tumor hypoxia for the outcome.

\section{HYPOXIA IMAGING IN OTHER ENTITIES}

So far, most studies on hypoxia imaging have been conducted in patients with cancers of the head and neck. There are few data regarding other entities, and to our knowledge there are no data available for serial hypoxia imaging.

In uterine cervix carcinoma, 18-F-FETNIM-PET uptake was associated with a worse prognosis (41). However, for pancreatic cancer - known to be often hypoxic - results of a recent imaging study with 18-F-MISO-PET were not promising (42). Another small study with four heterogeneous gastrointestinal cancers, one lung cancer, and one uterine cancer showed no hypoxia for the lung cancer, a slight decrease in hypoxic subvolume for the uterine cancer $(42.3-36.5 \%)$ and a mixed response for the gastrointestinal cancers: three relatively strong reductions and one slight increase (28).

In this regard, it will be interesting to see the results of an on-going exploratory study assessing serial 18-F-MISO-PET and serial functional MRI for non-small cell lung cancer (43).

\section{CLINICAL IMPLICATIONS}

Given the findings discussed so far, it is important to consider possible implications not only for research, but also for the clinical setting. One way to address hypoxic subvolumes is through dose painting. This approach aims at delivering higher doses to potentially more radioresistant parts of a tumor. The possibility and feasibility of using hypoxia imaging in a clinical setting in head and neck cancer patients - e.g., as a template for dose painting - has already been shown $(14,44-47)$.

To-date, there are no clinical studies comparing the effects on response and outcome of an altered radiation regimen aiming at hypoxic subvolumes with a standard course of treatment.

Therefore, possible effects on the outcome can only be hypothesized; plan comparisons predict higher tumor control probabilities when delivering a $10-\mathrm{Gy}$ simultaneous integrated boost to hypoxic subvolumes identified with a 18-F-MISO-PET-scan prior to treatment in an IMRT plan (48). An increased tumor control probability has also been calculated by Chang et al. (49), who compared a hypoxic subvolume-directed boost (total dose $84 \mathrm{~Gy}$ ) with a standard plan $(70 \mathrm{~Gy})$ and a uniform dose escalation plan (84 Gy). In this study, the dose escalation to the hypoxic subvolume was found to be superior to the other plans. However, the clinical significance of these findings needs further investigation, ideally in a randomized controlled clinical trial. But there are also other aspects which have to be considered for radiation treatment planning, for example the number of fractions and fraction size (e.g., hypofractionation as one option with increased effectiveness) (50). Still, the radiobiology of radiation-induced changes in hypoxic subvolumes is not fully understood, with the effects of hypoxia on the outcome also depending on the tumor type and other characteristics (8).

On the other hand, based on the dynamic components of hypoxia, it has been questioned whether or not dose painting on potentially geographically unstable structures makes sense (51). There is no definite answer to this question yet, but a rather stable geographical location may advocate a possible inclusion into radiation treatment planning.

If hypoxia imaging is to be used in a clinical setting, the identification of the best time frame for image acquisition has also to be considered: on the one hand, most studies showed a substantial decrease of the amount of hypoxia in the course of treatment, with little or no residual hypoxia at the end of treatment (implying advantages of early imaging). On the other hand, at the beginning of treatment, a high proportion of patients seem to be partly hypoxic (implying advantages of later imaging). Taking into account these two possibly conflicting aspects, it has been suggested to use image data acquired after the first or second week of treatment [e.g., $(25,29)]$. So far, this seems to be the most reliable timing for image acquisition.

Another possible intervention is the use of additional drugs or other modifiers specifically aiming at tumor hypoxia. Several studies have been performed, and a number of agents are currently under consideration. Especially nitroimidazoles, now known for their use as hypoxia-specific tracers, have been studied extensively due to their known hypoxia sensitizing effect (50). Other modifications include the inspiration of normobaric or hyperbaric oxygen, attempting to increase oxygen level and supply. In a recent meta-analysis, the positive effects of these interventions on locoregional control and overall survival - without thereby increasing the rate of complication - have been shown (50). Other targets include tumor vessels, e.g., by using VEGF, HIF-1alpha, or PI3K/Akt/mTOR inhibitors (52). Evidence for the use of these agents mostly comes from in vitro and (early) in vivo studies, and clinical evidence is rare. However, some drugs which have been in use for a long time for other indications revealed positive effects on tumor hypoxia and have recently been further studied in this regard. Prominent examples include HIV protease inhibitors such as Nelfinavir, currently studied in clinical trials (53).

\section{CONCLUSION}

Hypoxic subvolumes in cancers of the head and neck are significantly associated with response to therapy and outcome. In the time-course of treatment, the characteristics of these subvolumes change. Few studies have addressed these changes so far. Major findings point toward a remarkable reduction in tumor hypoxia during treatment and a geographically rather stable conformation. However, more intense research is needed to further characterize the development of tumor hypoxia during treatment.

\section{ACKNOWLEDGMENTS}

The article processing charge was funded by the German Research Foundation (DFG) and the Albert Ludwigs University Freiburg in the funding programme Open Access Publishing. 


\section{REFERENCES}

1. Begg AC. Predicting recurrence after radiotherapy in head and neck cancer. Semin Radiat Oncol (2012) 22(2):108-18. doi:10.1016/j. semradonc.2011.12.002

2. Brizel DM, Sibley GS, Prosnitz LR, Scher RL, Dewhirst MW. Tumor hypoxia adversely affects the prognosis of carcinoma of the head and neck. Int J Radat Oncol Biol Phys (1997) 38:285-9. doi:10.1016/ S0360-3016(97)00101-6

3. Nordsmark M, Overgaard J. A confirmatory prognostic study on oxygenation status and loco-regional control in advanced head and neck squamous cell carcinoma treated by radiation therapy. Radiother Oncol (2000) 57:39-43. doi:10. 1016/S0167-8140(00)00223-1

4. Eschmann SM, Paulsen F, Reimold M, Dittmann H, Welz S, Reischl G, et al. Prognostic impact of hypoxia imaging with $18 \mathrm{~F}$-misonidazole PET in non-small cell lung cancer and head and neck cancer before radiotherapy. J Nucl Med (2005) 46(2):253-60.

5. Rischin D, Hicks RJ, Fisher R, Binns D, Corry J, Porceddu S, et al. Trans-Tasman Radiation Oncology Group Study 98.02. Prognostic significance of $[18 \mathrm{~F}]$-misonidazole positron emission tomographydetected tumor hypoxia in patients with advanced head and neck cancer randomly assigned to chemoradiation with or without tirapazamine: a substudy of Trans-Tasman Radiation Oncology Group Study 98.02. J Clin Oncol (2006) 24(13): 2098-104.

6. Rajendran JG, Schwartz DL, O’Sullivan J, Peterson LM, Ng P, Scharnhorst J, et al. Tumor hypoxia imaging with [F-18] fluoromisonidazole positron emission tomography in head and neck cancer. Clin Cancer Res (2006) 12(18):5435-41. doi:10.1158/10780432.CCR-05-1773

7. Kikuchi M, Yamane T, Shinohara S, Fujiwara K, Hori SY, Tona Y, et al. 18F-fluoromisonidazole positron emission tomography before treatment is a predictor of radiotherapy outcome and survival prognosis in patients with head and neck squamous cell carcinoma. Ann Nucl Med (2011) 25(9):625-33. doi:10.1007/s12149-011-0508-9

8. Horsman MR, Mortensen LS, Petersen JB, Busk M, Overgaard J. Imaging hypoxia to improve radiotherapy outcome. Nat Rev Clin Oncol (2012) 9(12):674-87. doi:10.1038/nrclinonc.2012.171
9. Srinivasan A, Mohan S, Mukherji SK. Biologic imaging of head and neck cancer: the present and the future. AJNR Am J Neuroradiol (2012) 33(4):586-94. doi:10.3174/ ajnr.A2535

10. Gagel B, Reinartz P, Dimartino E, Zimny M, Pinkawa M, Maneschi P, et al. pO(2) Polarography versus positron emission tomography ([(18)F] fluoromisonidazole, [(18)F]-2-fluoro-2'-deoxyglucose). An appraisal of radiotherapeutically relevant hypoxia. Strahlenther Onkol (2004) 180(10):616-22. doi:10.1007/s00066-004-1229-y

11. Zimny M, Gagel B, DiMartino E, Hamacher $\mathrm{K}$, Coenen $\mathrm{HH}$, Westhofen M, et al. FDG - a marker of tumour hypoxia? A comparison with [18F]fluoromisonidazole and pO2-polarography in metastatic head and neck cancer. Eur J Nucl Med Mol Imaging (2006) 33(12):1426-31. doi:10.1007/s00259-006-0175-6

12. Mortensen LS, Buus S, Nordsmark M, Bentzen L, Munk OL, Keiding S, et al. Identifying hypoxia in human tumors: a correlation study between 18F-FMISO PET and the Eppendorf oxygen-sensitive electrode. Acta Oncol (2010) 49(7):934-40. doi:10. 3109/0284186X.2010.516274

13. Gagel B, Piroth M, Pinkawa M, Reinartz P, Zimny M, Kaiser HJ, et al. pO polarography, contrast enhanced color duplex sonography (CDS), [18F] fluoromisonidazole and [18F] fluorodeoxyglucose positron emission tomography: validated methods for the evaluation of therapy-relevant tumor oxygenation or only bricks in the puzzle of tumor hypoxia? BMC Cancer (2007) 28(7):113. doi:10.1186/ 1471-2407-7-113

14. Souvatzoglou M, Grosu AL, Röper B, Krause BJ, Beck R, Reischl $\mathrm{G}$, et al. Tumour hypoxia imaging with [18F]FAZA PET in head and neck cancer patients: a pilot study. Eur J Nucl Med Mol Imaging (2007) 34(10):1566-75. doi:10. 1007/s00259-007-0424-3

15. Postema EJ, McEwan AJ, Riauka TA, Kumar P, Richmond DA, Abrams DN, et al. Initial results of hypoxia imaging using 1alpha-D: $\quad-(5$-deoxy-5-[18F]fluoroarabinofuranosyl)-2nitroimidazole (18F-FAZA). Eur J Nucl Med Mol Imaging (2009) 36(10):1565-73. doi:10.1007/s00259-009-1154-5

16. Minagawa Y, Shizukuishi K, Koike I, Horiuchi C, Watanuki K, Hata M, et al. Assessment of tumor hypoxia by
62Cu-ATSM PET/CT as a predictor of response in head and neck cancer: a pilot study. Ann Nucl Med (2011) 25(5):339-45. doi:10.1007/s12149011-0471-5

17. Komar G, Seppänen M, Eskola O, Lindholm P, Grönroos TJ, Forsback S, et al. 18F-EF5: a new PET tracer for imaging hypoxia in head and neck cancer. $J \mathrm{Nucl}$ Med (2008) 49(12):1944-51. doi:10. 2967/jnumed.108.053785

18. Chen L, Zhang Z, Kolb HC, Walsh JC, Zhang J, Guan Y. ${ }^{18} \mathrm{~F}-\mathrm{HX} 4$ hypoxia imaging with PET/CT in head and neck cancer: a comparison with ${ }^{18}$ F-FMISO. Nucl Med Commun (2012) 33(10):1096-102. doi: 10.1097/MNM.0b013e3283571016

19. Thorwarth D, Eschmann SM, Scheiderbauer J, Paulsen F, Alber M. Kinetic analysis of dynamic 18Ffluoromisonidazole PET correlates with radiation treatment outcome in head-and-neck cancer. BMC Cancer (2005) 5:152. doi:10.1186/ 1471-2407-5-152

20. Wang W, Georgi JC, Nehmeh SA, Narayanan M, Paulus T, Bal M, et al. Evaluation of a compartmental model for estimating tumor hypoxia via FMISO dynamic PET imaging. Phys Med Biol (2009) 54(10):3083-99. doi:10.1088/00319155/54/10/008

21. Shi K, Souvatzoglou M, Astner ST, Vaupel P, Nüsslin F, Wilkens JJ, et al. Quantitative assessment of hypoxia kinetic models by a crossstudy of dynamic 18F-FAZA and $15 \mathrm{O}-\mathrm{H} 2 \mathrm{O}$ in patients with head and neck tumors. J Nucl Med (2010) 51(9):1386-94. doi:10.2967/ jnumed.109.074336

22. Newbold K, Castellano I, CharlesEdwards E, Mears D, Sohaib A, Leach $M$, et al. An exploratory study into the role of dynamic contrast-enhanced magnetic resonance imaging or perfusion computed tomography for detection of intratumoral hypoxia in head-andneck cancer. Int J Radiat Oncol Biol Phys (2009) 74(1):29-37. doi:10. 1016/j.ijrobp.2008.07.039

23. Truong MT, Saito N, Ozonoff A, Wang J, Lee R, Qureshi MM, et al. Prediction of locoregional control in head and neck squamous cell carcinoma with serial CT perfusion during radiotherapy. AJNR Am J Neuroradiol (2011) 32(7):1195201. doi:10.3174/ajnr.A2501

24. Lee N, Nehmeh S, Schöder H, Fury M, Chan K, Ling CC, et al. Prospective trial incorporating pre-/midtreatment [18F]-misonidazole positron emission tomography for head-and-neck cancer patients undergoing concurrent chemoradiotherapy. Int $J$ Radiat Oncol Biol Phys (2009) 75(1):101-8. doi:10.1016/j.ijrobp.2008.10.049

25. Zips D, Zöphel K, Abolmaali N, Perrin R, Abramyuk A, Haase R, et al. Exploratory prospective trial of hypoxia-specific PET imaging during radiochemotherapy in patients with locally advanced head-andneck cancer. Radiother Oncol (2012) 105(1):21-8. doi:10.1016/j.radonc. 2012.08.019

26. Dirix P, Vandecaveye V, De Keyzer F, Stroobants S, Hermans R, Nuyts $S$. Dose painting in radiotherapy for head and neck squamous cell carcinoma: value of repeated functional imaging with (18)F-FDG PET, (18)F-fluoromisonidazole PET, diffusion-weighted MRI, and dynamic contrast-enhanced MRI J Nucl Med (2009) 50(7):1020-7. doi:10.2967/jnumed.109.062638

27. Mortensen LS, Johansen J, Kallehauge J, Primdahl $H$, Busk $M$, Lassen $P$, et al. FAZA PET/CT hypoxia imaging in patients with squamous cell carcinoma of the head and neck treated with radiotherapy: results from the DAHANCA 24 trial. Radiother Oncol (2012) 105(1):14-20. doi:10.1016/j.radonc.2012.09.015

28. Tachibana I, Nishimura Y, Shibata T, Kanamori S, Nakamatsu K, Koike $\mathrm{R}$, et al. A prospective clinical trial of tumor hypoxia imaging with $18 \mathrm{~F}$-fluoromisonidazole positron emission tomography and computed tomography (F-MISO $\mathrm{PET} / \mathrm{CT}$ ) before and during radiation therapy. J Radiat Res (2013). doi:10.1093/jrr/rrt033. [Epub ahead of print].

29. Bittner MI, Wiedenmann N, Bucher S, Hentschel M, Mix M, Weber WA, et al. Exploratory geographical analysis of hypoxic subvolumes using 18F-MISO-PET imaging in patients with head and neck cancer in the course of primary chemoradiotherapy. Radiother Oncol (2013). doi:10.1016/j. radonc.2013.06.012. [Epub ahead of print].

30. Lin Z, Mechalakos J, Nehmeh S, Schoder H, Lee N, Humm J, et al. The influence of changes in tumor hypoxia on dose-painting treatment plans based on 18FFMISO positron emission tomography. Int J Radiat Oncol Biol Phys (2008) 70(4):1219-28. doi:10.1016/ j.ijrobp.2007.09.050

31. Nehmeh SA, Lee NY, Schröder H, Squire O, Zanzonico PB, Erdi 
YE, et al. Reproducibility of intratumor distribution of (18)Ffluoromisonidazole in head and neck cancer. Int J Radiat Oncol Biol Phys (2008) 70(1):235-42. doi:10.1016/j.ijrobp.2007.08.036

32. Okamoto $S$, Shiga $T$, Yasuda $K$, Ito $\mathrm{YM}$, Magota $\mathrm{K}$, Kasai $\mathrm{K}$, et al. High reproducibility of tumor hypoxia evaluated by $18 \mathrm{~F}-$ fluoromisonidazole PET for head and neck cancer. J Nucl Med (2013) 54(2):201-7. doi:10.2967/jnumed. 112.109330

33. Mönnich D, Troost EG, Kaanders JH, Oyen WJ, Alber M, Thorwarth D. Modelling and simulation of the influence of acute and chronic hypoxia on $\quad[18 \mathrm{~F}]$ fluoromisonidazole PET imaging. Phys Med Biol (2012) 57(6):1675-84. doi:10.1088/0031-9155/57/6/1675

34. Toma-Dasu I, Uhrdin J, Antonovic L, Dasu A, Nuyts S, Dirix P, et al. Dose prescription and treatment planning based on FMISO-PET hypoxia. Acta Oncol (2012) 51(2):222-30. doi:10.3109/ 0284186X.2011.599815

35. Stadler P, Feldmann HJ, Creighton C, Kau R, Molls M. Changes in tumor oxygenation during combined treatment with split-course radiotherapy and chemotherapy in patients with head and neck cancer. Radiother Oncol (1998) 48(2):157-64. doi:10.1016/S01678140(98)00032-2

36. Thorwarth D, Eschmann SM, Paulsen F, Alber M. A model of reoxygenation dynamics of head-and-neck tumors based on serial 18F-fluoromisonidazole positron emission tomography investigations. Int $J$ Radiat Oncol Biol Phys (2007) 68(2):515-21. doi:10.1016/j.ijrobp.2006.12.037

37. Eschmann SM, Paulsen F, Bedeshem C, Machulla HJ, Hehr T, Bamberg $M$, et al. Hypoxia-imaging with (18)FMisonidazole and PET: changes of kinetics during radiotherapy of head-and-neck cancer. Radiother Oncol (2007) 83(3): 406-10. doi:10.1016/j.radonc.2007. 05.014

38. Hicks RJ, Rischin D, Fisher R, Binns D, Scott AM, Peters LJ. Utility of FMISO PET in advanced head and neck cancer treated with chemoradiation incorporating a hypoxia-targeting chemotherapy agent. Eur J Nucl Med Mol Imaging (2005) 32(12):1384-91. doi:10. 1007/s00259-005-1880-2

39. Wang K, Yorke E, Nehmeh SA, Humm JL, Ling CC. Modeling acute and chronic hypoxia using serial images of 18F-FMISO PET. Med Phys (2009) 36(10):4400-8. doi:10. 1118/1.3213092

40. Sun Q, Li X, Lu X, Di B. Cancer stem cells may be mostly maintained by fluctuating hypoxia. Med Hypotheses (2011) 76(4):471-3. doi: 10.1016/j.mehy.2010.11.023

41. Vercellino L, Groheux D, Thoury A, Delord M, Schlageter MH, Delpech $\mathrm{Y}$, et al. Hypoxia imaging of uterine cervix carcinoma with (18)FFETNIM PET/CT. Clin Nucl Med (2012) 37(11):1065-8. doi:10.1097/ RLU.0b013e3182638e7e

42. Segard T, Robins PD, Yusoff IF, Ee H, Morandeau L, Campbell $\mathrm{EM}$, et al. Detection of hypoxia with $18 \mathrm{~F}$-fluoromisonidazole (18FFMISO) PET/CT in suspected or proven pancreatic cancer. $\mathrm{Clin} \mathrm{Nucl}$ Med (2013) 38(1):1-6. doi:10.1097/ RLU.0b013e3182708777

43. Askoxylakis V, Dinkel J, Eichinger M, Stieltjes B, Sommer G, Strauss LG, et al. Multimodal hypoxia imaging and intensity modulated radiation therapy for unresectable nonsmall-cell lung cancer: the HIL trial. Radiat Oncol (2012) 14(7):157. doi: 10.1186/1748-717X-7-157

44. Grosu AL, Souvatzoglou M, Röper B, Dobritz M, Wiedenmann N, Jacob V, et al. Hypoxia imaging with FAZA-PET and theoretical considerations with regard to dose painting for individualization of radiotherapy in patients with head and neck cancer. Int J Radiat Oncol Biol Phys (2007) 69(2):541-51. doi: 10.1016/j.ijrobp.2007.05.079

45. Lee NY, Mechalakos JG, Nehmeh S, Lin Z, Squire OD, Cai $S$, et al. Fluorine-18-labeled fluoromisonidazole positron emission and computed tomography-guided intensity-modulated radiotherapy for head and neck cancer: a feasibility study. Int J Radiat Oncol Biol Phys (2008) 70(1):2-13. doi:10. 1016/j.ijrobp.2007.06.039

46. Thorwarth D, Eschmann SM, Paulsen F, Alber M. Hypoxia dose painting by numbers: a planning study. Int $J$ Radiat Oncol Biol Phys (2007) 68(1):291-300. doi:10.1016/j.ijrobp.2006.11.061

47. Thorwarth D, Alber M. Individualised radiotherapy on the basis of functional imaging with FMISO PET. Z Med Phys (2008) 18(1):43-50. doi:10.1016/j.zemedi. 2007.08.003

48. Hendrickson K, Phillips M, Smith W, Peterson L, Krohn K, Rajendran J. Hypoxia imaging with [F18] FMISO-PET in head and neck cancer: potential for guiding intensity modulated radiation therapy in overcoming hypoxia-induced treatment resistance. Radiother Oncol (2012) 101(3):369-75. doi:10.1016/ j.radonc.2011.07.029

49. Chang JH, Wada M, Anderson NJ, Lim Joon D, Lee ST, Gong SJ, et al. Hypoxia-targeted radiotherapy dose painting for head and neck cancer using (18)F-FMISO PET: a biological modeling study. Acta Oncol (2013). doi:10.3109/ 0284186X.2012.759273. [Epub ahead of print].

50. Overgaard J. Hypoxic modification of radiotherapy in squamous cell carcinoma of the head and neck - a systematic review and meta-analysis. Radiother Oncol (2011) 100(1):22-32. doi:10.1016/j. radonc.2011.03.004
51. Quon H, Brizel DM. Predictive and prognostic role of functional imaging of head and neck squamous cell carcinomas. Semin Radiat Oncol (2012) 22(3):220-32. doi:10.1016/j. semradonc.2012.03.007

52. Karar J, Maity A. Modulating the tumor microenvironment to increase radiation responsiveness. Cancer Biol Ther (2009) 8(21):1994-2001. doi:10.4161/cbt.8.21.9988

53. Pore N, Gupta AK, Cerniglia GJ, Jiang Z, Bernhard EJ, Evans SM, et al. Nelfinavir down-regulates hypoxia-inducible factor lalpha and VEGF expression and increases tumor oxygenation: implications for radiotherapy. Cancer Res (2006) 66(18):9252-9. doi:10.1158/00085472.CAN-06- 1239

Conflict of Interest Statement: The authors declare that the research was conducted in the absence of any commercial or financial relationships that could be construed as a potential conflict of interest.

Received: 22 May 2013; paper pending published: 01 July 2013; accepted: 13 August 2013; published online: 28 August 2013.

Citation: Bittner MI and Grosu $A L$ (2013) Hypoxia in head and neck tumors: characteristics and development during therapy. Front. Oncol. 3:223. doi: 10.3389/fonc. 2013.00223

This article was submitted to Radiation Oncology, a section of the journal Frontiers in Oncology.

Copyright (c) 2013 Bittner and Grosu. This is an open-access article distributed under the terms of the Creative Commons Attribution License (CC BY). The use, distribution or reproduction in other forums is permitted, provided the original author(s) or licensor are credited and that the original publication in this journal is cited, in accordance with accepted academic practice. No use, distribution or reproduction is permitted which does not comply with these terms. 